\title{
Evaluation of the Antibacterial Activity of Jatropha multifida sap and Artemisia annua Extract on some Clinical Strains Responsible of Urinary Tract Infections
}

\author{
Dougnon Victorien ${ }^{1,2 *}$, Sovegnon Toussaint ${ }^{1}$, Agbankpe Jerrold ${ }^{1}$, Aniambossou Alidah ${ }^{1}$, \\ Amadou Afoussatou ${ }^{1}$, Dougnon Jacques ${ }^{1}$ and Baba-Moussa Lamine ${ }^{2}$ \\ 'Research Unit in Applied Microbiology and Pharmacology of Natural Substances (U.R.M.A. Pha), \\ Polytechnic School of Abomey-Calavi (EPAC), University of Abomey-Calavi (UAC), 01 BP 2009 Cotonou, Benin; \\ victorien88@hotmail.com, sovegnontoussaint@yahoo.fr, jerroldagbankpe@yahoo.fr, \\ anialidah@outlook.fr, hafsoth@yahoo.fr, dougnonj@yahoo.fr \\ ${ }^{2}$ Laboratory of Biology and Molecular Typing in Microbiology, Faculty of Science and Technology, \\ University of Abomey-Calavi, UAC, 05 PO Box 1604, Cotonou, Benin; \\ laminesaid@yahoo.fr
}

\begin{abstract}
Objectives: The present study aims to evaluate the antibacterial activity of Jatropha multifida sap and aqueous extract of Artemisia annua leaves on some clinical strains responsible of urinary tract infection. Methods: The bacterial strains were isolated after the cytobacteriological examination of the collected urine. The agar and liquid diffusion methods were used for the sensitivity test and the determination of the Minimal Inhibitory Concentration (MIC) and Minimum Bactericidal Concentration (MBC) of plant extracts on isolated strains. Findings: Ten bacterial strains isolated from the urine samples were collected. Isolated bacteria exhibited various resistant profiles. As for the antibacterial activity evaluated on the leaves and sap collected, the aqueous extract of the leaves of Artemisia annua had no effect on the strains studied. The MICs and CMBs of Jatropha multifida sap vary according to the bacterial strains studied. Thus, the sap of Jatropha multifida has a bactericidal activity on all strains studied with the exception of the strain of Escherichia coli on which its action is more moderate. At the end of the work, the most isolated bacterial species are respectively Citrobacter freundii (40\%), Staphyloccocus aureus (30\%) and Klebsiella pneumoniae (20\%). All isolated clinical strains are multiresistant. The aqueous extract of Artemisia annua at $600 \mathrm{mg} / \mathrm{ml}$ showed no antimicrobial activity on the strains studied. Improvements: The sap of Jatropha multifida shows a bactericidal activity against the various strains tested and could therefore be an alternative to antibiotics following transformations into improved traditional medicines.
\end{abstract}

Keywords: Antibacterial Activity, Artemisia Annua, Clinical Strains, Jatropha Multifida, Urinary Tract Infections

\section{Introduction}

Urinary tract infections can affect one or more parts of the urinary system: Kidneys, ureters, bladder and urethra. They are most often manifested by pain or a

${ }^{*}$ Author for correspondence 
burning sensation when urinating (the emission of urine), sometimes by abdominal pain and fever ${ }^{1}$. The most commonly involved bacteria are Escherichia coli, Enterococcus spp., Pseudomonas aeruginosa and Staphylococci in descending order ${ }^{2}$. In more than $80 \%$ of urinary tract infections, the causative organism is an intestinal Escherichia coli ${ }^{3}$. As for Staphylococcus aureus, it is often diagnosed at an advanced stage of genitourinary infections $(43 \%)^{4}$.

Antibiotic therapy is the method used to treat this infection. But nowadays, bacterial resistance to antibiotics becomes recurrent and poses a global public health problem. The overall resistance rate of hospital and community enterobacterial strains to amoxicillin associated with the beta-lactamase, quinolone, fluoroquinolone, sulfamethoxazole + trimethoprim and nitrofuran inhibitors is high ${ }^{5}$.

In Africa and Asia, $80 \%$ of the population continues to use traditional medicines rather than so-called modern medicines for primary health care. The widespread use of traditional medicine in developing countries is due to the availability of plant resources used and often affordable. Healthcare professionals and the general public worldwide are struggling with the issues of safety, efficacy, quality, availability, preservation and future development of this type of health care ${ }^{6}$. Thus, many medicinal plants are used in traditional medicine among which include Jatropha multifida and Artemisia annua. Jatropha multifida with highly recognized medicinal properties is used to treat various diseases in Africa, Asia or Latin America? The antibacterial effect of leaves, stems and roots has been reported in various studies $\frac{7-9}{}$. The prescription of its juice in the management of oral candidiasis is a common practice among rural residents of western Nigeria. In Chinese medicine, the bark and leaves are used against itchy skin and eczema ${ }^{10}$. Jatropha multifida Linn. is one of the medicinal plants whose sap is widely used for healing wounds in Benin ${ }^{11}$. As for Artemisia annua L. (Asteraceae), has been used for centuries in traditional Asian medicine for the treatment and prevention of fever and chills. Antioxidant, anti-inflammatory and antimicrobial properties of leaf extracts of Artemisia annua have been reported $\underline{12}$.

It is in order to find a natural alternative, an affordable solution, accessible to all and effective to fight the resistance of the bacteria responsible for urinary tract infections that the present work is initiated. Thus, the general objective of this study was to evaluate the antibacterial activity of extracts of Jatropha multifida and Artemisia annua on some clinical strains incriminated in urinary tract infections.

\section{Material}

\subsection{Plant Material}

The plant material consists of the sap of Jatropha multifida Linn which was collected in the commune of AbomeyCalavi. Sampling was done directly in the sterile tubes after cutting branches of Jatropha multifida Linn and then stored at $4^{\circ} \mathrm{C}$ in the refrigerator.

With regard to Artemisia annua, the dried leaves and stems of the plant packaged and sold commercially by the house of Artemisia were used.

\subsection{Biological Material}

It consists of 45 urine samples of patients collected for two weeks at the Allada Zone Hospital Laboratory, Menontin Area Hospital and Calavi Area Hospital. All of these patients had come to the laboratory for reasons of infection etiology. Two reference strains (Escherichia coli ATCC 2552 and Staphylococcus aureus ATCC 2552) provided by the laboratory of U.R.M.A.Pha were also exploited.

\subsection{Other Material and Equipment}

The usual culture media in bacteriology have been used for culture and isolation of bacteria. Reagents and dyes such as: Kovacs reagent, gentian violet, lugol, $90^{\circ}$ alcohol, fuschine solution diluted 1/10, methylene blue, hydrogen peroxide and fresh plasma rabbit were used to identify bacteria. 
Several equipment were also used namely: The optical microscope, the refrigerator, the oven, the autoclave, the poupinel, the centrifuge, the balance of precision, the bunsen burner and the rack. Sterile Petri dishes, hemolysis tubes and sterile screw tubes, TPHA plates, swabs, antibiotic discs, anaerobiosis jar and gloves.

\section{Methods}

\subsection{Determination of the Resistance Profile of Clinical Strains Isolated from Urinary Tract Infections}

The prospective study for analytical purposes was conducted over a period of one month from March 18 to April 18, 2019. It took into account the cytobacteriological examination of 45 urine samples collected from patients received during the period collection. The bacteriological manipulations were carried out in four days. The first day was devoted to the reception of biological samples, the identification of samples, the macroscopic examination, the microscopic examination and the cultivation. The reading of the seeded media, the realization of Gram control and isolation for obtaining pure strain followed on the second day. On the third day, the identification at the classic Leminor gallery and the antibiogram were realized then read on the fourth day.

\subsection{Antibacterial Activity of Jatropha multifida sap and Artemisia annua}

\section{Leaf Extract on some Clinical Strains Responsible for Urinary Tract Infection}

The sap of Jatropha multifida Linn has been directly tested on isolated strains. As for Artemisia annua, the aqueous extract of the leaves and stems of the plant was prepared and tested on isolated strains. The total aqueous extracts were obtained by an adaptation of the method developed by ${ }^{13}$. Fifty (50) grams of powder was macerated in 500 $\mathrm{ml}$ of distilled water. The mixture is stirred continuously (Stuart Bioblock Scientific Fisher shaker) for 72 hours at room temperature. The homogenate obtained was filtered three times on hydrophilic cotton and once on Wattman No. 1 paper. This filtrate was then dried at $45^{\circ} \mathrm{C}$. in the oven. The powder thus obtained is the total aqueous extract used.

\subsection{Preparation of Extracts}

The aqueous extract of Artemisia annua was taken up in distilled water at a rate of $100 \mathrm{mg}$ per $1 \mathrm{ml}$. The stock solutions thus concentrated to $100 \mathrm{mg} / \mathrm{ml}$ were then autoclaved at $121^{\circ} \mathrm{C}$. for 15 minutes. Sterility of stock extract solutions was verified by inoculating aliquots of each solution onto Mueller Hinton medium and incubated at $37^{\circ} \mathrm{C}$ for 24 hours. The absence of colonies on the Mueller Hinton medium after 48 hours confirmed the sterility of these mother extracts solutions. Regarding Jatropha multifia, sap was used. The concentration of the whole sap of this plant has been estimated at $320 \mathrm{mg} / \mathrm{ml}$ according to the work done by ${ }^{11}$ on the exploration of the antibacterial properties and the healing power of Jatropha multifida Linn. sap in the rat Wistar.

The yield of the crude extract is defined as the ratio between the mass of the dry extract obtained and the mass of the treated plant material. This yield was calculated via the equation: $\mathrm{R}(\%)=\mathrm{Me} / \mathrm{Mv} \times 100$ with $\mathrm{R}(\%)$ : Yield, Me: Mass of the extract after the evaporation of the solvent and Mv: Mass of the plant material used for extraction.

\subsection{Test of Antimicrobial Activity carried out on Agar by the Diffusion Method}

A bacterial preculture (1 colony in $5 \mathrm{ml}$ of sterile distilled water) of $18 \mathrm{~h}$ was diluted to obtain a turbidity of $0.5 \mathrm{on}$ the McFarland scale (ie $108 \mathrm{CFU} / \mathrm{ml}$ ). Each inoculum was seeded by swabbing onto petri dishes containing Mueller Hinton agar (CA-SFM, 2012). Using the sterile pasteur pipette tip $6 \mathrm{~mm}$ diameter wells were dug. Then using a sterile cone and a micropipette $50 \mu \mathrm{l}$ of each extract was deposited in previously dug wells. A well containing sterile distilled water served as a negative control. Standard antibiotic discs have also been used to serve as positive controls. The dishes were left for 15 minutes at room temperature for pre-diffusion before being incubated 
Table 1. Standard used for reading the results of antibiogram tests of plant extracts

\begin{tabular}{|c|c|c|}
\hline Inhibition zone diameter $(\boldsymbol{\Delta})$ & Degree of sensitivity of the germ & Symbol \\
\hline$\Delta<7 \mathrm{~mm}$ & Insensitive & - \\
\hline $7 \mathrm{~mm} \leq \Delta<8 \mathrm{~mm}$ & Sensitive & + \\
\hline $8 \mathrm{~mm} \leq \Delta<9 \mathrm{~mm}$ & Pretty sensitive & ++ \\
\hline$\Delta \geq 9 \mathrm{~mm}$ & Very sensitive & +++ \\
\hline
\end{tabular}

$\Delta \quad$ : Inhibition zone diameter

- $\quad$ : insensitive

$+\quad$ : Sensitive

$+\quad$ : Pretty sensitive

$++\quad$ : Very sensitive

Source: WHO, 2002; Tsirinirindravo and Andrianarisoa, 2009
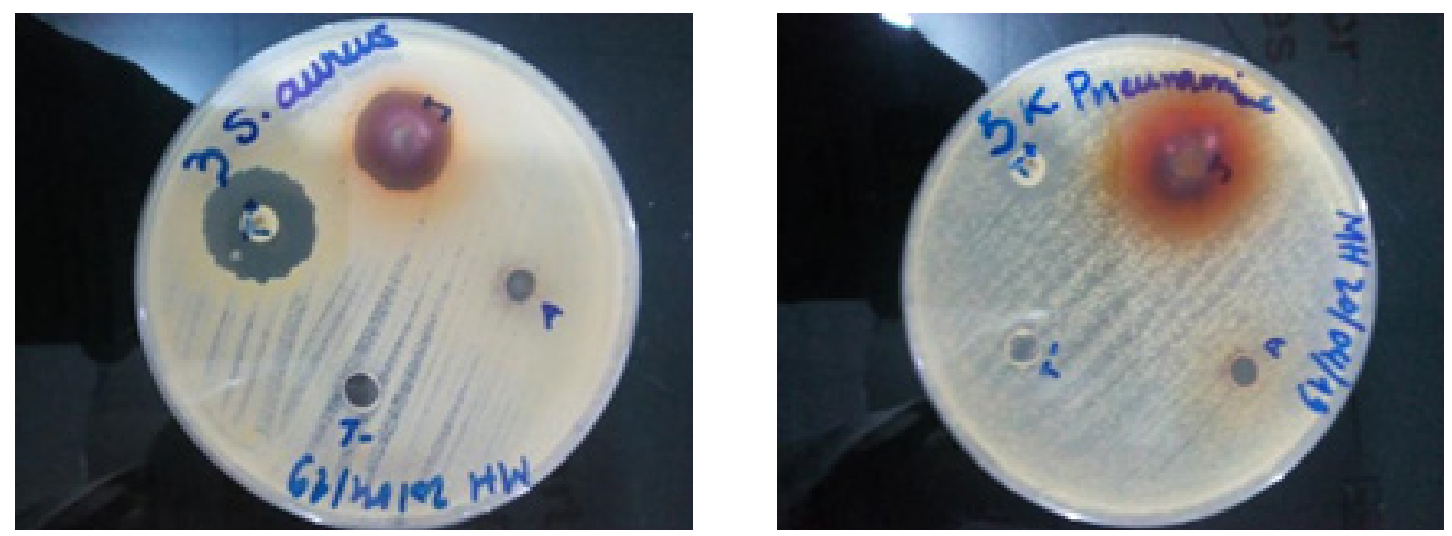

Image 1. Determination of inhibition diameter .

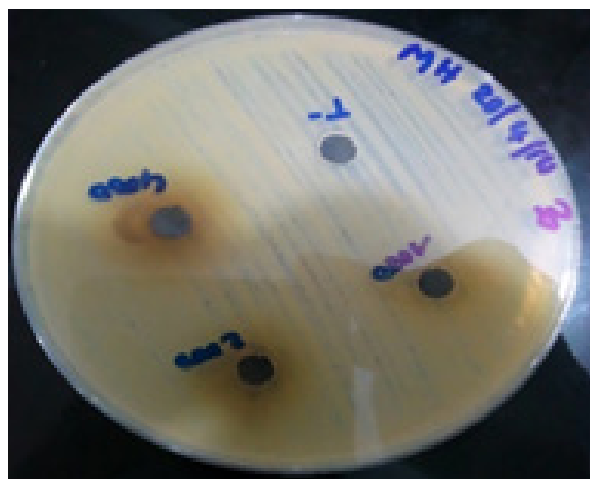

Image 2. Determination of inhibition diameters of Artemisia annua.

at $37^{\circ} \mathrm{C}$ for 24 hours. After the incubation period, the dishes were examined to record any zones of inhibition (diameter measured in $\mathrm{mm}$ ) (Table 1). All tests were done in duplicate. (Images 1, 2). 


\subsection{Determination of the Minimal} Inhibitory Concentration (MIC) by Micro Dilution and the Minimal Bactericidal Concentration (CMB)

An extract stock solution was prepared at the concentration of $100 \mathrm{mg} / \mathrm{ml}$ in distilled water. $100 \mu \mathrm{l}$ of Mueller-Hinton Broth medium (MHB) were placed in each well of the microplate (wells 1 to 8 ). $100 \mu$ lof the extract stock solution were deposited in the first well. After homogenization by suction-discharge using a micropipette, $200 \mu \mathrm{l}$ of a solution of extract at $100 \mathrm{mg} / \mathrm{ml}$ are obtained. $100 \mu \mathrm{l}$ of this new solution were taken and mixed with the MHB medium contained in the 2 nd well and this series of dilution of reason 2 from wells to wells is continued until the 6th well, from which the $100 \mu \mathrm{l}$ are discarded. Finally $100 \mu \mathrm{l}$ of the bacterial suspension were added to each well. The 7 th and 8 th wells were respectively the positive control and the negative control and contain $100 \mu \mathrm{l}$ of $\mathrm{MHB}+100 \mu \mathrm{l}$ of bacterial suspension for the positive control and $100 \mu \mathrm{l}$ of MHB for the negative control. The microplates were covered for 24 hours in an oven at $37^{\circ} \mathrm{C}$.
MICs were estimated visually compared to controls. As for the $\mathrm{CMB}$, it was determined after seeding the contents of each well on the $\mathrm{MH}$ agar and incubated at $37^{\circ} \mathrm{C}$ for 24 hours. $\mathrm{CMB}$ was the lowest concentration of extract for which there were no bacterial colonies.

\subsection{Data Processing and Analysis}

The collection of information and the analysis of the tables were carried out using the Excel 2013 software. The graphs were made with the Graph Pad software. Descriptive statistics were performed using SPSS 20.ng.

\section{Results}

\subsection{Bacterial Profile of Strains Isolated from Urine Samples}

Of 45 samples collected, 10 were positive (22.22\%) and 35 negative (77.78\%). The majority of the samples came from women $(78 \%)$, of which $20 \%$ were positive and

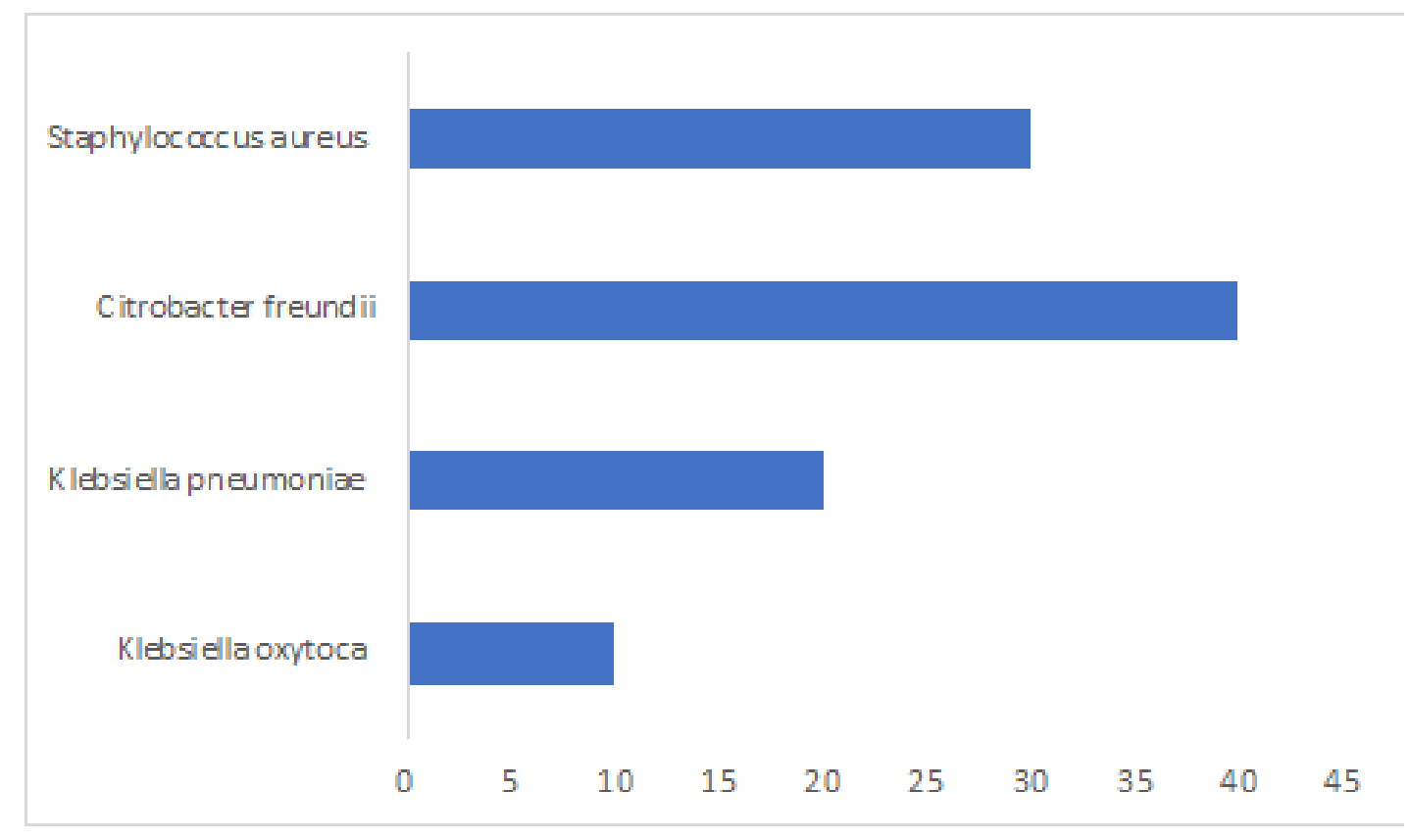

Figure 1. Frequencies of isolated microorganisms. 
Table 2. Resistance profile of isolated bacterial strains

\begin{tabular}{|c|c|c|}
\hline \multicolumn{2}{|l|}{ Strains } & Resistance profile \\
\hline Klebsiella oxytoca & 1 & $A M C^{R} N F E^{S} C R O^{R} C O X^{R} G M N^{R} C I P^{R} F A D^{R}$ \\
\hline \multirow{4}{*}{ Citrobacter freundii } & 1 & $A M C^{S} C O X^{S} C R O^{S} G M N^{S} N F E^{R} C I P^{R} S X T^{R}$ \\
\hline & 2 & $A M C^{R} C O X^{R} C R O^{S} G M N^{R} N F E^{S} S X T^{R} C I P^{S} F A D^{R}$ \\
\hline & 3 & $A M C^{R} G M N^{S} C H L^{R} C I P^{S} C O X^{R} C R O^{S} F A D^{R}$ \\
\hline & 4 & $A M C^{R} N F E^{S} G M N^{R} C O X^{R} C R O^{S} F A D^{R} C I P^{R}$ \\
\hline \multirow{2}{*}{ K. pneumoniae } & 1 & $A M C^{R} N F E^{R} G M N^{R} C R O^{R} C O X^{R} C I P^{R} S X T^{R}$ \\
\hline & 2 & $A M C^{S} N F E^{R} G M N^{S} C H L^{R} C I P^{S} C R O^{R} C O X^{R}$ \\
\hline \multirow{3}{*}{ Staphylococcus aureus } & 1 & $A M P^{S} O X A^{S} N F E^{S} G M N^{R} E R Y^{S} L C N^{S} F O X^{R} C H L^{R}$ \\
\hline & 2 & $A M P^{R} A M C^{S} N F E^{S} G M N^{R} E R Y^{R} L C N^{R} F O X^{R} C H L^{R}$ \\
\hline & 3 & $A M P^{S} A M C^{S} N F E^{S} G M N^{R} E R Y^{R} L C N^{R} F O X^{R} C H L^{R}$ \\
\hline
\end{tabular}

$\mathrm{S}=$ Sensitive; $\mathrm{R}=$ Résistant

AMP = Ampicillin $;$ AMC = Amoxicillin + clavulanicacid; NFE = Nitrofurantoin; GMN = Gentamycin;

$\mathrm{ERY}=$ Erythromycin; LCN = Lincomycin; FOX = Cefoxitin; CHL = Chloranphenicol; CRO = Ceftriaxone;

$\mathrm{COX}=$ Cefotaxime; GMN = Gentamicin; CIP = Ciprofloxacin; ADF = Fusidicacid;

$58 \%$ negative. Only $22 \%$ of the samples came from men with $2 \%$ positive samples versus $20 \%$ negative samples. Citrobacter freundii was the most isolated bacterium (40\%) followed by Staphylococcus aureus (30\%) (Figure 1).

Table 2 shows the resistance profile of the isolated bacterial strains. It shows that all isolated bacterial strains have resistance to several families of antibiotics, most of which exceed three different families of antibiotics. These strains are therefore all multi-resistant (Table 2).

\subsection{Antibacterial Activity of Extracts}

\subsubsection{Extraction Yields}

The aqueous extract of the leaves and stems of Artemisia annua has a yield of $23.72 \%$. The sterility tests revealed the absence of contamination in the extract and sap of Jatrophamultifida.

\subsubsection{Sensitivity Test}

The strains tested, at the concentration of $100 \mathrm{mg} / \mathrm{ml}$ showed a variable sensitivity to the extracts tested. The inhibition diameters of the extracts varied between 7 and $21 \mathrm{~mm}$. The sap of Jatropha multifida was active on all bacterial strains tested. In contrast to the aqueous extract of Artemisia annua that showed no antimicrobial activity.

Increasing the concentration of the aqueous extract of Artemisia annua had no effect on the isolated strains including the reference strains. Thus, the aqueous extract tested at various concentrations $(100,200,400$ and 800 $\mathrm{mg} / \mathrm{ml}$ ) on the isolated strains and on the reference strains 
Table 3. Inhibition diameter of extracts of the plants studied on isolated bacterial clinical strains

\begin{tabular}{|c|c|c|c|c|c|c|c|c|c|c|c|c|}
\hline Species Plants / Bacteria & 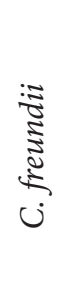 & 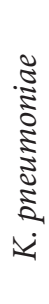 & 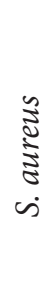 & 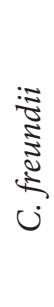 & 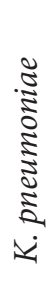 & $\begin{array}{l}\hat{3} \\
\tilde{\Xi} \\
\bar{\Xi} \\
\dot{s}\end{array}$ & $\begin{array}{l}\tilde{3} \\
\tilde{3} \\
\bar{\Xi} \\
\dot{\omega}\end{array}$ & ن & $\underbrace{:=}_{i}$ & 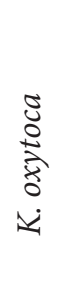 & 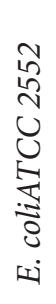 & 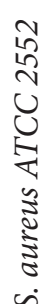 \\
\hline $\begin{array}{l}\text { SE Jatropha multifida }(320 \mathrm{mg} / \\
\mathrm{ml} / \text { agar plate) }\end{array}$ & 16 & 10 & 17 & 11 & 18 & 16 & 13 & 9 & 10 & 12 & 07 & 21 \\
\hline $\begin{array}{l}\text { E. Artemisia annua }(100 \mathrm{mg} / \mathrm{ml} / \\
\text { agar plate })\end{array}$ & 0 & 0 & 0 & 0 & 0 & 0 & 0 & 0 & 0 & 0 & 0 & $\mathbf{0}$ \\
\hline
\end{tabular}

$\mathrm{SE}=$ Whole sap of Jatrophamultifida; $\mathrm{E}=$ Aqueous extract of Artemisia annua

(E. coli ATCC2552 and S. aureus ATCC2552) showed no antibacterial activity (Table 3).

\subsection{Minimal Inhibitory Concentration, Minimal Bactericidal Concentration and Antibiotic Potency of Jatropha multifida Sap}

The Minimum Inhibitory Concentrations (MIC) obtained is variable depending on the types of strains. The lowest MICs were obtained at a concentration of $40 \mathrm{mg}$. Minimum Bactericidal Concentrations (MBC) also varied with the type of susceptible strains. Antibiotic potency (a.p) was determined using the $\mathrm{CMB} / \mathrm{MIC}$ ratio. The $\mathrm{CMB} / \mathrm{MIC}$ ratio of the Jatrophamultifida sap on Klebsiella pneumoniae, Citrobacter freundii, Staphylococcus aureus and Klebsiella oxytoca is less than 4 . The Jatropha multifida sap therefore has a bactericidal effect on these strains (Table 4).

Table 4. MIC, CMB and antibiotic potency (a .p.) of the sap of Jatropha multifida

\begin{tabular}{|c|c|c|c|c|c|c|c|c|c|c|c|c|c|}
\hline \multirow[b]{2}{*}{ 䔍 } & \multirow[b]{2}{*}{ 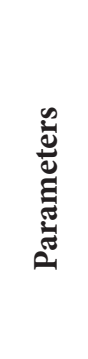 } & \multicolumn{11}{|c|}{ Bacterial strains } & \multirow[b]{2}{*}{ 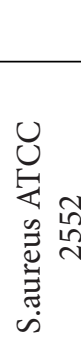 } \\
\hline & & 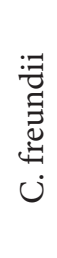 & 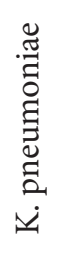 & 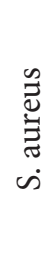 & $\begin{array}{l}: \exists \\
\underset{\Xi}{\Xi} \\
\stackrel{\Xi}{\Xi} \\
ن\end{array}$ & 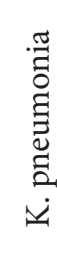 & 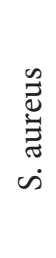 & 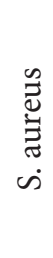 & 节 & 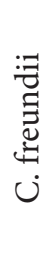 & 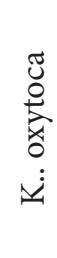 & 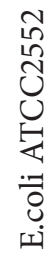 & \\
\hline \multirow{3}{*}{$\begin{array}{l}\text { Jatropha } \\
\text { multifida sap }\end{array}$} & MIC & 40 & - & 20 & - & 80 & 40 & - & 40 & 40 & 80 & - & 40 \\
\hline & $\mathrm{CMB}$ & 40 & - & 40 & - & 160 & 40 & - & 80 & 80 & 160 & 80 & 40 \\
\hline & p. a. & 1 & - & 2 & - & 2 & 1 & - & 2 & 2 & 2 & - & 1 \\
\hline
\end{tabular}

P.a $=$ Antibiotic power MIC $=$ Minimum inhibitory concentration $; \mathrm{CMB}=$ Minimal Bactericidal Concentration 


\section{Discussion}

The present study evaluated the antibacterial properties of plant extracts of Artemisia annua (leaf and stem), Jatropha multifida (sap) on bacterial species responsible for urinary tract infections. The study found that the most isolated bacteria are respectively Citrobacter freundii (40\%) Staphylococcus aureus (30\%), Klebsiella pneumoniae (20\%), and Klebsiella oxytoca (10\%). The resistance profile of the isolated strains shows that they are all multiresistant. The aqueous extract of leaf and stem of Artemisia annua showed no antibacterial activity on the strains tested regardless of the concentration. On the other hand, mainly with a minimum bactericidal concentration of $40 \mathrm{mg} / \mathrm{ml}$, the sap of Jatropha multifida had a bactericidal activity on the majority of the strains tested despite their multi-resistance to the usual antibiotic disks.

The results obtained from the antibacterial activity showed that the 12 strains studied were sensitive to the sap of J. multifida including the two reference strains but to varying degrees. In fact, the growth of most of the strains studied was totally inhibited by the Jatropha multifida sap with a minimum MIC of $20 \mathrm{mg} / \mathrm{ml}$ whereas the Escherichia coli strain was only moderately sensitive. Indeed, the flavonoids, tannins and terpenes identified during phytochemical screening have strong antimicrobial activities $\frac{14,15}{}$. These compounds were responsible for the antimicrobial activity of the leaf extract of Melastoma malabathricum because of their antibacterial properties ${ }^{16}$.

Other authors have achieved results similar to ours by studying the antimicrobial activity of different parts of Jatropha multifida. Indeed, Jatropha multifida sap from the University of Ibadan in Nigeria has completely inhibited S. aureus, E. coli and other bacteria ${ }^{17}$. In ${ }^{18} 2007$, aqueous and ethanolic extracts of J. multifida leaves were active on E. coli and S. aureus.

Similar results were noted in a study on the leaves, stems, roots of Jatropha multifid ${ }^{19}$. Although these results are similar, MICs differ in terms of effect on strains. In Nigeria, a MIC of $0.78 \mu \mathrm{g} / \mathrm{ml}$ for S. aureus was obtained in 2008 with the leaves and roots of the plant (19) $16 \mathrm{mg} /$ $\mathrm{ml}, 66 \mathrm{mg} / \mathrm{ml}$ and $263 \mathrm{mg} / \mathrm{ml}$ were noted respectively for S. aureus, E. coli and K. pneumoniae with the sap of Jatropha multifida in 2014 ${ }^{20}$. The difference in sensitivity obtained between the saps of Nigeria and Benin could be related to environmental factors (pedographic, climatic), the strains tested and the method used.

With regard to the aqueous extract of Artemisia annua, these results are contrary to the results obtained during the work carried out on the antibacterial, antioxidant and anti-inflammatory activity of Artemisinin extracted from Artemisia annualinn²1. These results are explained by the fact that our study took into account only the aqueous extract of this plant and that the strains tested are different. The quality of the extract varies according to the solvent used during extraction ${ }^{22}$. It will be necessary to make other extracts of the plant with different solvent in addition to distilled water to better evaluate the antibacterial properties of this plant.

Medicinal plants are therefore a good alternative to antibiotics facing the multi-resistance bacterial observed today. It is very important to carry out various investigations on the properties necessary for a better qualification of these plants in order to minimize any risk to health.

\section{Conclusion}

At the end of this work, we can remember that the most isolated bacteria are enterobacteria including Citrobacter freundii and Staphylococci. All isolated strains show strong resistance to antibiotics. In the light of the results obtained from the antibacterial activity of the extracts, it should be remembered that the Jatropha multifida sap has good and well antibacterial properties on the multi-resistant strains of K. pneumoniae, K. oxytaoca, C. freundii, S. aureus isolated urine samples which is not the case for the aqueous extract of Artemisia annua (leaves and stems) which had no activity on isolated strains and reference strains.

It is therefore necessary to initiate additional in vitro and in vivo studies necessary to expand the database on 
the antibacterial properties and toxicity of these plants. The craze for medicinal plants should shift from a mere fad to a research, investment and sustainable development perspective of aromatic and medicinal plants for health and well-being purposes.

\section{References}

1. Urinary Tract Infections (UTIs). 2019. https://www.webmd. com/women/guide/your-guide-urinary-tract-infections\# 1 .

2. Bacteriological aspects of nosocomial urinary tract infections. 2003. https://www.researchgate.net/ publication/263450216_Bacteriological_aspects_of_ nosocomial_urinary_tract_infections.

3. Urinary Infection: Symptoms, treatments and prevention. 2019. https://www.sahealth.sa.gov.au/wps/ $\mathrm{wcm} /$ connect/public+content/sa+health+internet/ health+topics/health+conditions+prevention + and + tr eatment/infectious+diseases/urinary+tract+infection/ urinary+tract+infection+uti+-+including+symptoms+trea tment+and+prevention.

4. Duarte C, Alexander T, Hermínia L. Secrets of success of a human pathogen: Molecular evolution of pandemic clones of methicillin resistant Staphylococcus aureus. Infectious Diseases. 2002; 2:180-9. https://doi.org/10.1016/S14733099(02)00227-X.

5. Lahlou A, Chegri M, L'Kassmi H. Epidemiology and antibiotic resistance of enterobacteria isolated from urinary tract infections at the Moulay-Ismail military hospital in Meknes. Antibiotics. 2009; 11:90-6. https://doi. org/10.1016/j.antib.2008.10.004.

6. WHO Strategy for Traditional Medicine for 2002-2005. 2002. https://apps.who.int/medicinedocs/en/d/Js2297e/.

7. Aiyelaagbe O, Bola J, Babatunde D, Bola A. Antibacterial activity of Jatropha multifida roots. Fitoterapia. 2001; 72:544-6. https://doi.org/10.1016/S0367-326X(00)00291-4.

8. Aiyelaagbe O, Bola J, Babatunde D, Bola A. The antimicrobial activity of Jatropha multifida extracts and chromatographic fractions against sexually transmitted infections. Journal of Medical Sciences. 2008; 8(2):143-7. https://doi. org/10.3923/jms.2008.143.147.

9. Hamza O, van den Bout-van den B, Matee M, Mikx F, Selemani H, Van der Ven J, Verweij E. Antifungal activity of some Tanzanian plants traditionally used for treatment of fungal infections. Journal of Ethnopharmacology. 2006; 108:124-32. PMid: 16829001. https://doi.org/10.1016/j. jep.2006.04.026.

10. Klotoe JR, Jean Marc A, Victorien D, Frederic L, Karim D. Jatropha multifida Linn. (euphorbiaceae): Exploration of the antibacterial properties and healing power of the sap of this plant in Wistar albino rats. Review of Microbiology Industrial Sanitary and Environmental. 2014; 8(2):120-32.

11. Kim W, Woo J, Sunwoo L, Woo J, Dong C, Dong S, HyoungShik S, Wonyong K. Anti-inflammatory, antioxidant and antimicrobial effects of Artemisinin extracts from Artemisia annua L. Korean Journal of Physiology and Pharmacology. 2015; 19:21-7. PMid: 25605993 PMCid: PMC4297758. https://doi.org/10.4196/kjpp.2015.19.1.21.

12. Efferth T. From ancient herb to modern drug: Artemisia annua and artemisinin for cancer therapy. Seminars in Cancer Biology. 2017; 46:65-83. PMid: 28254675. https:// doi.org/10.1016/j.semcancer.2017.02.009.

13. Agban A, Falodun U, Okunrobo O, Uzoamaka N. Evaluation of the antimicrobial activities of Tridax procumbens (Asteraceae), Jatropha multifida (Euphorbiaceae) and Chromolaena odorata (Asteraceae). European Scientific Journal. 2013. p. 1857-7881..

14. James O, Emmanuel T. Phytochemical composition, bioactivity and healing of leaf extract of Euphorbia heterophylla (Euphorbiaceae). International Journal of Pharmaceutical and Biomedical Research. 2010; 1(1):54$63 .$.

15. Nurdiana S, Attama A, Uzor P, Nnadi C, Okafor C. The healing activities of Melastoma malabathricum's wounds with leaf extract in Sprague Dawley Rats. Journal and Research of the International Journal of Pharmaceutical Sciences. 2013; 20(2):20-3..

16. Aransiola M, Charles E, Joy C, Idris O. Antibacterial and antifungal activities of Jatropha multifida (Ogege) sap against certain pathogens. Journal of Pharmacy and Biological Sciences. 2014; 9:53-7. https://doi.org/10.9790/300809415357.

17. Adesola A, Adetunji O. The efficacy of Jatropha multifida in the management of oral candidiasis: Preliminary study. The Internet Journal of Alternative Medicine. 2007; 4(1):66-8. https://doi.org/10.5580/23e.

18. Dalia H, Mohamed L, Sri M, Assem E, Michael W. Chemical composition of the essential oils of variegated pink-fleshed lemon (Citrus $\mathrm{x}$ limon L. Burm. f.) and their anti-inflammatory and antimicrobial activities. Zeitschrift fur Naturforschung C. 2013. p. 275-84. https://doi. org/10.1515/znc-2013-7-804.

19. Alaa A, Gaafar A, Salama S. Phenolic compounds from artichoke (Cynara scolymus L.) byproducts and their antimicrobial activities. Journal of Biology, Agriculture and Healthcare. 2013; 3(12):1-7..

20. A multi-agent approach for the design of ambient intelligence systems: A formal model integrating planning and learning [Ph.D. thesis]. 2015. https://www. 
researchgate. net/publication/281298878_A_multi-agent_ approach_for_ambient_system_design_A_formal_model_ incorporating_planning_and_learning.

21. Elfawal M, Mostafa A, Elfawal M, Nicholas G, Pamela J, Weathers A. Artemisia annua, a dried whole plant, slows down the development of antimalarial drug resistance and overcomes artemisinin resistance. Proceedings of the National Academy of Sciences of the United States of America. 2011; 112:821-6. PMid: 25561559 PMCid: PMC4311864. https://doi.org/10.1073/pnas.1413127112.

22. Walsh C. Antibiotics: Actions, origins, resistance. American Society of Microbiology (ASM). Protein Sci. 2004; 13(11):3059-60. 